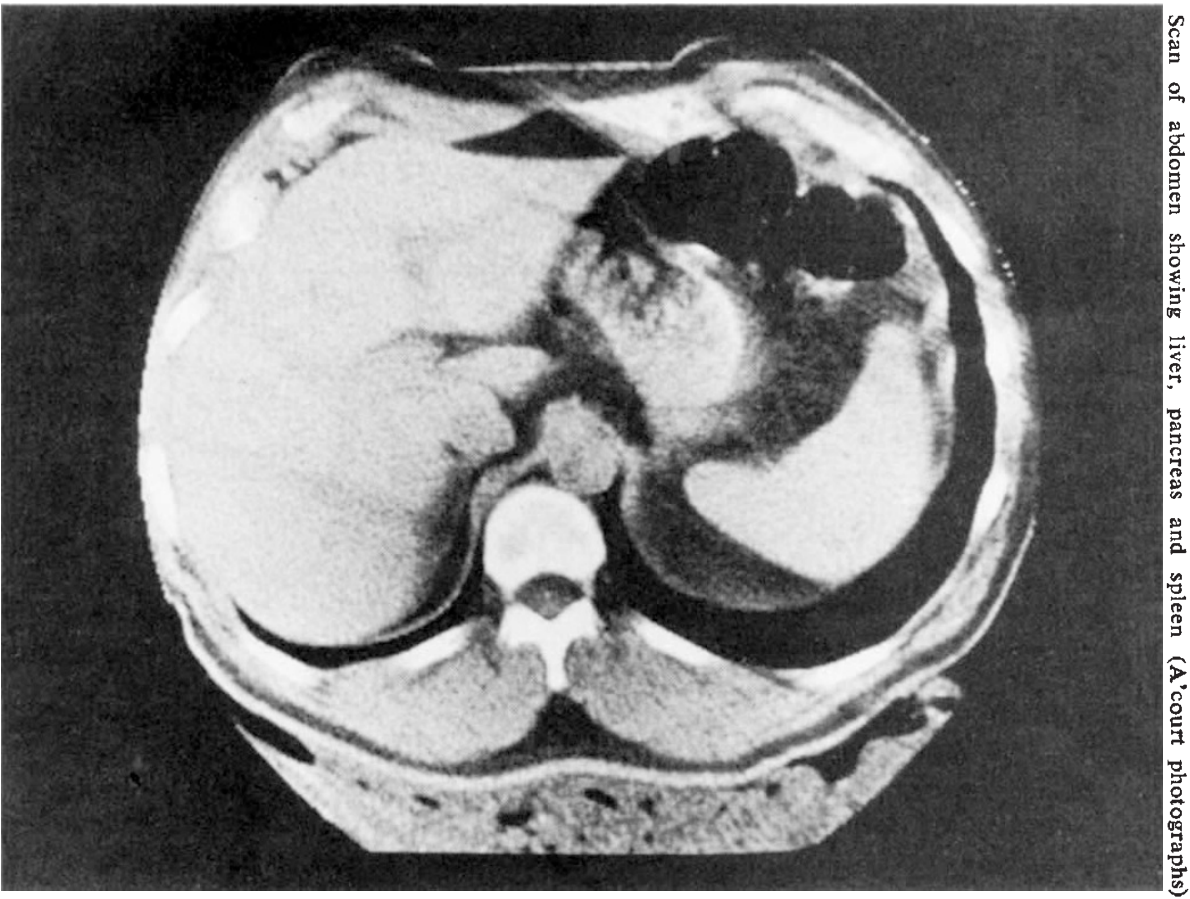

\section{Harnessing electronics to medicine}

As world resources are turned increasingly towards ameliorating environmental problems and improving the health of the population, the growth of electronic technology in medicine is well under way. But one of the crucial factors that will determine the advance is finance. Bernard Watson reports on a trend now represented most popularly by the EMI scanner.

A NYONE who has found himself in a hospital at various times since the Second World War could not have failed to notice the increasing sophistication of the equipment used to diagnose ailments and monitor the progress back to health. Modern technology and medicine now work hand in hand, and continue to open up new vistas.

The development of machines for the automatic chemical analysis of blood and new radio-immuno assay techniques for hormones has contributed to a rapid increase in laboratory diagnostic techniques. Ion sensing electrodes will soon be available which will bring back to the bedside the measurements hitherto made in the laboratory; indwelling electrodes, being miniaturised versions of those used for in vitro determinations, will be used for continuous monitoring, while semiconductor probes, such as ion sensing field effect transistors, may also become available.

Laboratory measurements like these supplement the measurements made by direct attachment to the patient. Cardioscopes and arrhythmia detectors, which may include computer surveillance of patients, are to be found in the intensive care and coronary care wards, as are automatic respirators.
Indeed, the whole array of life support systems has reached a high degree of complexity.

Therapeutic advances have also been made. The electronic pacemaker is now accepted and even implanted in the aged patient. The artificial kidney has advanced from the early Keel parallel plate dialyser, using cellophane as a membrane, to the disposable capillary kidney, though the cost remains a major disadvantage. This could give way to the wearable kidney with absorbents, or to the development of the storage of donor organs to such a degree of sophistication that matching can take place over months instead of lost a limb will soon include electronic feedback from muscle groups that are still able to signal the brain's commands, provided implantation of the device is accepted. Electronic aids for the blind will also improve. And if the electrical stimulation of the visual cortex to produce significant emanation of light (or "phosphenes") can be harnessed, together with a reduction in size of the solid state camera, the 'artificial eye' will be realised. A prosthesis for the deaf based on the producmore than 48 hours.

A prosthesis for the patient who has tion of "audenes", analogous to the "phosphenes", may be within reach as well.

Doppler ultrasonic blood flow measurement is now accepted as a useful technique for the vascular surgeon as well as the obstetrician, who uses it to record the foetal heart. Here, the ultrasonic energy is continuously transmitted, unlike the pulsed ultrasound used in echo scanning techniques. The red cell acts as an effective scatterer, and on the assumption that the velocity of the red cell and of the blood as a whole are correlated, it provides a moving target to follow in the vascular system. These meters at present measure blood velocity, but it should be possible to produce quantitative flow meters once the correct method of frequency analysis of the scattered ultrasound is discovered and techniques are developed for measuring the diameter of the artery.

The application of ultrasonic scanning has introduced a new dimension. Small piezoelectric crystals producing 1.5 or $5 \mathrm{MHz}$ ultrasound are coupled by means of oil or water to the skin. The crystals transmit and receive echoes from interfaces separating media of differing acoustic impedance. The third ventricle in the brain is just such a surface, so its displacement, which indicates intracranial pathology, can be measured with moderate ease.

The use of 'A scan' techniques in cardiology for recording the movement of the mitral valve enables the calcification of its leaflets to be assessed by non-invasive means. The separation of the myocardium and the epicardial sac due to infection can also be diagnosed and allows progressive changes to be assessed. The size of the heart and the dimensions of the left ventricle can also be measured. And switched crystal arrays will enable dynamic studies to be made, enabling the volume changes of the ventricle throughout the cardiac cycle to be measured using the techniques developed for angiocardiography. At present, contrast media must be injected and rapid multi-shot $\mathrm{X}$-ray techniques applied.

'B scan' ultrasound has made a significant contribution in gynaecology and obstetrics. Foetal life and growth can now be followed throughout pregnancy, and the placenta can be accurately located. Liver and kidney scans are also useful for the detecting of abnormal pathology.

The recent advance in thermography is also relevant, since the speed and resolution of the latest instruments permits the easy detection of perforating veins and the observation of peripheral vascular changes without the disturbance to the circulation caused by injecting contrast media or radioactive isotopes. It is also of use for 
detecting deep vein thrombosis. Although mammography using xeroradiography may be used for confirmation, the X-ray dose is still higher than that preferred for routine screening purposes, and thermography will be very useful for six-monthly checks.

These are but a few of the electronic devices which are available to the clinician. The most important advances, however, have been in diagnostic imaging. Previously the radiologist struggled for better definition of pathological and functional change in his patient using conventional X-rays with source, patient and plate in simple configurations. Now, the position of the patient and tube and the tube voltage can be more easily manipulated for better definition.

But the outstanding advance in this field has been the X-ray scanner developed by Geoffrey Hounsfield for EMI. Before the advent of this technique, the clinician had to rely on a barrage of techniques to detect intracranial pathology. The techniques depended on the preferential uptake of a radioactive isotope by the tumour, or the experienced eye of the neurophysiologist looking for changes in the EEG. Final confirmation involved an angiogram or an air encephalogram with their attendant risks.

Hounsfield's approach involves the measurement of the absorption of the soft tissue displayed, but its sophistication is that it gives a definition not seen before in radiology. The initial EMI scanner, moreover, which could only be used for the head, has been followed by a body scanner. The disadvantages of standard tomographic procedure are the indistinct picture of the layer under scrutiny and the superimposition of the blurred images of neighbouring layers.

In the body scanner, the patient is $\mathrm{X}$-rayed as a series of $13 \mathrm{~mm}$ thick tomographic sections. Each section is examined during each 20-second scanning sequence. The X-ray source and the detector array are mounted on a scanning frame contained in a gantry. A further detector records the intensity of the primary beam. The section is scanned linearly across the patient and the transmission intensity recorded, producing more than 18,000 readings during the scan. At the end of the scan the frame is moved $10^{\circ}$ and a further linear scan commences. The sequence is then repeated through a total of $180^{\circ}$.

The readings of intensity are digitised and analysed by a minicomputer to produce the absorption values at 80,000 points within each section. The magnetic store can store eight $13-\mathrm{mm}$ sections. The information for each slice is recorded in the form of a matrix of square picture elements contained within a circle of 320 picture points. A typical element represents an area in the slice of $1.25 \times 1.25 \mathrm{~mm}$ when the machine is set up for a $400-\mathrm{mm}$ body diameter, and $0.75 \times 0.75 \mathrm{~mm}$ at the smallest body diameter setting of $240 \mathrm{~mm}$. The absorption values are expressed in units from -500 to +500 , with water at 0 on the scale.

As a wide range of absorption values are recorded during the scanning procedure, a control allows a specific range of values to be displayed. The values are permanently recorded, so any range can be displayed on the television monitor. Bulk storage of patient data is readily available using magnetic tape. For the first time accurate measurements of absorption values to $\pm 0.25 \%$ are possible with adequate resolution for the analysis of pathological changes in the organ under examination. Clinical assessment of this technique is awaited, but early pictures demonstrate the detail that can be seen even by the inexperienced reader of radiographers.

Therapeutic applications must follow this development since the definition in the image gives positional information not previously available. The instruments for non-invasive investigation of most patients is now possible without trauma or risk of death, although the inherent danger of exposure to radiation remains. Better therapeutic techniques, and improvements in preventive medicine, are being sought, but therapeutic advances are not yet keeping pace with diagnostic skills.

If technology can produce advances in therapy and preventive medicine as well as contribute to improved social conditions, the recent advances in medicine will be fully realised and the new diagnostic techniques will produce more than just accurate data for analysing failures. Much, however, depends on the crucial factor of finance. In the UK, research and development in medical electronics is con- siderable but scattered over many hospitals as well as industrial and government research laboratories with little co-ordination. The Department of Health and Social Security (DHSS) has tried over the past 10 years to encourage specific developments where it has been able to define a need. Pacemakers with ever-greater reliability provide one example and work on these contributed to the development of the miniature nuclear battery for longerlife pacemakers. Companies will generally look for a promising home market before they invest since the overseas medical market is difficult to service and brings its own problems in differing safety standards and clinical approaches. In the case of the initial prototype EMI scanner, finance was provided jointly by the DHSS and EMI.

More could be done if resources were available, but the cost of development is escalating. Development facilities are presently lacking in the hospitals where therapeutic development could be done cheaply and effectively because of the close contact with clinical problems. A capital grant alone will not solve the problems, however. Trained personnel such as engineers and technicians are also needed to use the equipment and integrate it successfully into clinical medicine if there is to be more effective diagnosis and treatment. The development funds of the DHSS have increased more than five-fold during the past 10 years, but the exact level of expenditure is difficult to assess because of the diversity of the programme.

Health expenditure must increase as medical science unravels more of the diversity of disease processes. But the requirement that it be cost effective often causes administrators to wonder whether too much money is devoted to interesting but rare diseases. Animal experimentation might be preferred and it has its place, but it will never surpass carefully collected data from

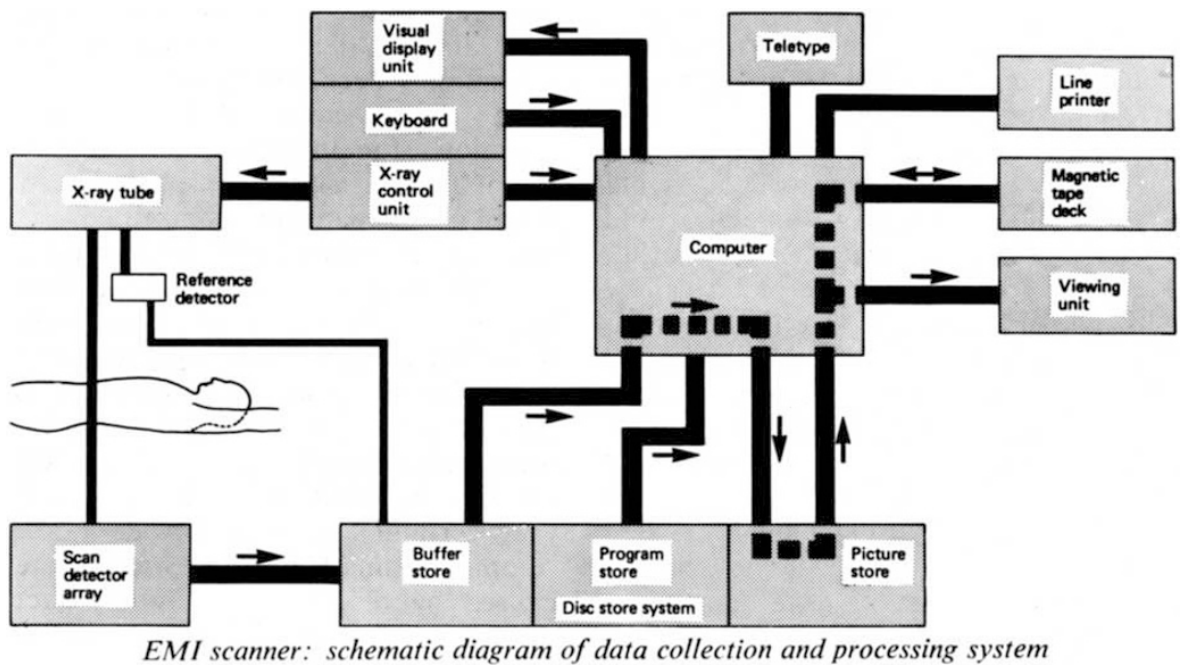

EMI scanner: schematic diagram of data collection and processing system 
sick patients. On the other hand, the clinician has little time to undertake applied research. Considerable improvement in medicine would occur if money could be provided to finance multidisciplinary teams on well-planned projects in which industry would collaborate by developing the necessary technology.

But at the moment the need to treat more patients than ever before clashes with increasingly rigid budgetary con- straints. As in so many areas, but particularly in research, a world of priorities means that the capacity to find technological solutions might exist but the economic encouragement often does not.
I have just returned from attending the Fourth International Conference on the Unity of the Sciences, held at the Waldorf-Astoria Hotel in New York from November 27-30. The subject of the conference was "The Centrality of Science and Absolute Values", and it was attended by some 350 of what the programme describes as "the world's most eminent scholars and scientists" from 60 different countries. Readers of Nature will remember the editorial, "Bringing men to the Moon", published on October 25 1974, just before the Third Conference was held in London last November. The editorial questioned the status of the International Cultural Foundation, which was sponsoring (and financing) the conference.

The Foundation was started by the Reverend Sun Myung Moon, who is also the founder of the Unification Church. This church has been severely criticised, mainly for its strong anticommunist views, and for what some consider its undue influence on young converts. The Nature article suggested that the participants in the conference might find that they were being used to give respectability to an organisation of which they did not entirely approve. Although the ICF exists as "a non-profit organisation dedicated to promoting academic, scientific, religious and cultural exchange among the countries of the world", critics have suggested that its aims may be less disinterested and more political.

The Fourth Conference included a few representatives from communistgoverned states. Invitations had been sent to several people in Soviet Russia, but these were not accepted-an experience not unknown to organisers of the most orthodox scientific gathering. But scientists came from Hungary, Poland and Yugoslavia. In 1974 India was not represented, but this time several Indians attended, as did Egyptians, Lebanese, Israelis, and many others from "third world" countries. As before, we had a galaxy of Nobel Laureates, in physics, chemistry, physiology and other subjects. Several theologians, including Jesuits and other Roman Catholics, as well as members of other sects and different religions, were among the participants. The social sciences were well represented.

Last year the advance announcements about the Third Conference listed eminent names of supporters and participants, some of whom later dissociated themselves with the organisation. The opinion was stated (in Nature and elsewhere) that this might have been done to try to secure wider

\section{Attending a Moon conference}

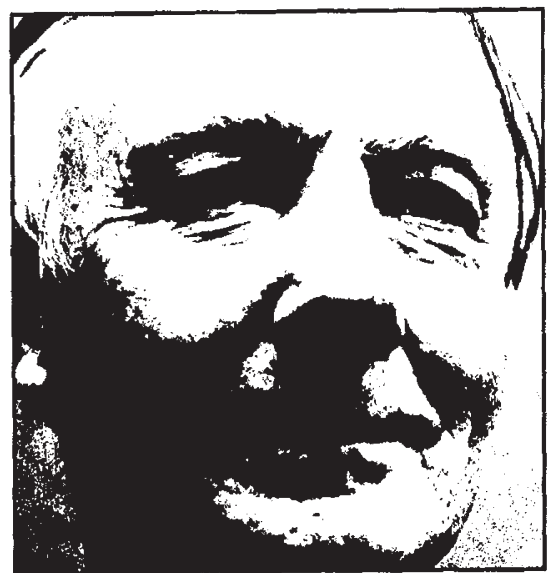

KENNETH MELLANBY

support. I believe that the use of any names without permission was due to misunderstanding -1 know one Briton who was approached who said he could not attend but " "would help if he could", and then objected when he was listed as a supporter. This year I do not think that anyone was named who was not genuinely willing to help.

Critics of the ICF have queried the selection of those invited, and of the programme of the conference. They have suggested that members may have allowed themselves to be put in a position where they could not freely state their views. Regarding the selection: the invitations came from the ICF, but names were chosen by entirely independent committees of advisers, American and international (I must confess to being one of their number). I do not know of any case in which a name was suggested and the individual was not invited It is true that the majority of members were middle-aged, and that few strident marxists were included but they certainly included a wide range of opinions and beliefs. Any gaps were caused by refusals, and by the fact that the advisers did not wish to include those, however well intentioned, who would wreck the event. In fact a few uncompromising critics did attend.

There was no censorship of views or opinions whatever. The 120 or so papers, which were previously circulated to the groups which discussed them, were read by the committee chairman, and sometimes authors were asked to shorten their text, but no matters of substance were excluded. As one who chaired a discussion group I can confirm that no one was muzzled. The conference certainly cannot be criticised as not allowing complete freedom of expression to all participants.

The $\$ 500,000$ question remains to be answered: was the conference worth while? I personally think that the answer is "yes". Many equally expensive international gatherings, even those dealing with important scientific topics, are clearly a waste of time and money. Litt'ie new is said or heard-_"Professor Blank read his paper" (the same one read so often before). Here we had a gathering of gocd men and women with good minds who seriously discussed the problems facing the world today, and the ways in which science could and s'lould be involved.

I know of no other gathering where this would have been possible. There was less nonsense talked than might have been expected-in my opening address I echoed a warning in last year's Nature, when I said that the present disenchantment of the public with science and scientists was "sometimes generated by scientists themselves-when they appear to speak as experts in fields where they possess no expertise".

We attempted to define the boundaries of the various branches of science, and the relations between the natural and social sciences. We discussed the problem of values, in regard to the family, to religion and to morality. Consideration was given to problems facing universities and research institutions, and to the ethics of the application of modern technology. The position of science in resolving world inequalities and in the creation of any fuure world order was also discussed. We did not solve all the world's outstanding problems, but perhaps we made some progress in the right direction. 